\title{
Clinical, patient-related, and economic outcomes of home-based high-dose hemodialysis versus conventional in-center hemodialysis
}

This article was published in the following Dove Press journal: International Journal of Nephrology and Renovascular Disease 5 July 2016

Number of times this article has been viewed

\section{Nicos Mitsides ${ }^{1,2}$ \\ Sandip Mitra ${ }^{1,2}$ \\ Tom Cornelis ${ }^{3}$}

'Department of Renal Medicine, Manchester Royal Infirmary, Central Manchester University Hospitals NHS Foundation Trust, Manchester Academic Health Science Center, Manchester, ${ }^{2}$ National Institute for Healthcare Research Devices for Dignity Healthcare Co-operative, Sheffield, UK; ${ }^{3}$ Department of Nephrology, Jessa Hospital, Hasselt, Belgium
Correspondence: Tom Cornelis Department of Nephrology, Jessa Hospital, Stadsomvaart II, 3500 Hasselt, Belgium Email tomcor77@gmail.com

\begin{abstract}
Despite technological advances in renal replacement therapy, the preservation of health and quality of life for individuals on dialysis still remains a challenge. The high morbidity and mortality in dialysis warrant further research and insight into the clinical domains of the technique and practice of this therapy. In the last 20 years, the focus of development in the field of hemodialysis (HD) has centered around adequate removal of urea and other associated toxins. High-dose HD offers an opportunity to improve mortality, morbidity, and quality of life of patients with end-stage kidney disease. However, the uptake of this modality is low, and the risk associated with the therapy is not fully understood. Recent studies have highlighted the evidence base and improved our understanding of this technique of dialysis. This article provides a review of high-dose and home HD, its clinical impact on patient outcome, and the controversies that exist.
\end{abstract}

Keywords: hemodialysis, home dialysis, high dose, outcomes

\section{Introduction}

End-stage renal disease (ESRD) is a life-changing condition that can significantly reduce both survival and quality of life (QoL) despite renal replacement therapy with dialysis. Although kidney transplantation provides the best health-related outcomes in ESRD, this is not feasible for many patients due to lack of organ availability. In the absence of transplantation, the most widely prescribed dialysis modality is hemodialysis (HD).

For 7 decades dialysis has been the lifeline treatment for chronic kidney disease (CKD) for $>2$ million people worldwide. Nevertheless, despite technological advances in the field, HD performed in a conventional thrice-weekly regime continues to carry a sevenfold increased mortality when compared to the general population and a suboptimal QoL with a high economic burden to the society. ${ }^{1-3}$ In contrast to native kidneys, HD is performed on an intermittent basis, leading to unphysiologic fluctuations of the internal milieu of the patient. Furthermore, dialysis techniques are less efficient in the clearance of larger uremic toxins. The increased mortality observed in the dialysis population is predominantly due to an increased risk of cardiovascular events, although infectious complications also play a significant role., ${ }^{4,5}$

The increased cardiovascular risk for dialysis patients in the short term is due to hemodynamic instability with episodes of intradialytic hypotension, acute cardiac events, including myocardial infarction, arrhythmias, and myocardial stunning. ${ }^{6-12}$ In particular, intradialytic hypotension may even result in further complications of 
myocardial or cerebral ischemia, especially in patients with preexisting cardiac and/or cerebrovascular disease. In the longer term, dialysis patients suffer from left ventricular hypertrophy (LVH), cardiovascular calcifications, global systolic dysfunction due to repetitive myocardial stunning, and arterial hypertension. ${ }^{8,13,14}$ Impaired fluid homeostasis is also responsible for many of the cardiovascular complications associated with HD as patients have to confront with large swings in fluid overload balance. The 72-hour interdialytic interval for the thrice-weekly HD regimens also poses a threat and is associated with an increased risk of cardiovascular mortality. ${ }^{15}$

\section{What is high-dose and home HD?}

Current practice entails that most HD patients receive their treatment in hospital or at a community-based satellite unit, three times a week for a minimum duration of 4 hours per session (conventional HD). Home-based HD, with its origins in the 1960s, rapidly waned in practice in the 1980s and 1990s but is undergoing a significant revival over the last 10 years. ${ }^{16}$ The combination of patient empowerment provided by the flexible nature of home-based HD regimes and the emergence of growing data supporting the association of such regimes with improved outcomes, such as survival, patient-reported QoL, and cost-effectiveness, are the primary drivers for this resurgence. ${ }^{17-19}$

Some of the improved outcomes associated with home HD can be linked with more intensive dialysis regimes and its prescription (high-dose HD) enabled by the flexibility of schedule in the home environment. Charra et $\mathrm{al}^{20}$ reported a dramatic improvement in survival of dialysis patients in Tassin by extending the length of HD session duration. High-dose HD refers to HD regimes that provide $>12$ hours per week of HD. This could be in the form of either increased dialysis frequency (number of treatment days per week) and/or prolonged session duration beyond the conventional 4 hours per treatment session. There are three predominant high-dose HD schedules that are commonly identified: 1) short-daily HD (SDHD) is performed
5-6 days per week utilizing shorter HD treatment session duration (2-3 hours); 2) long HD refers to prolonging the dialysis session duration ( $>4$ hours, could be up to 8 hours); and 3 ) extended (long-frequent) HD involves an increase in both frequency and length of the HD session. Both long and long-frequent HD can be provided overnight while the patient sleeps (nocturnal HD [NHD]). In some health care systems, SDHD and NHD can be delivered in the hospital, but it is ideal for high-dose HD regimes to be delivered in the home setting (high-dose home HD) in order to deliver maximal clinical effectiveness. Typical prescriptions of conventional and high-dose HD regimes are summarized in Table $1 .^{21}$

\section{Clinical benefits of high-dose HD}

The amount of dialysis delivered during conventional regime is often limited by the overall weekly treatment time and frequency. To deliver the minimum adequate dialysis, conventional regimes utilize high-efficiency dialysis over a short period of time. The resulting peaks and troughs of both hydration status and uremic solute concentrations between body compartments can lead to sharp changes in the internal milieu. More frequent and/or prolonged HD sessions can reduce the fluctuations of the internal environment by maintaining a more steady state, optimized by subtle adjustments to fluid and uremic toxin removal, and by avoidance of long interdialytic intervals. A summary of the benefits of high-dose HD is presented in Table 2. ${ }^{22}$

The survival benefit for patients undergoing SDHD and NHD has been evaluated in a number of studies. However, no well-powered randomized controlled trial (RCT) has been performed to date, and the bulk of the data remain observational. The evidence points toward a better survival for patients receiving SDHD and NHD compared to those treated with conventional regimes. ${ }^{23-30}$ Some studies would even suggest that the survival benefit of SDHD and NHD is comparable to that of deceased donor transplant recipients, ${ }^{31,32}$ although in the most recent retrospective cohort study of high-dose home HD patients and kidney transplant recipients,

Table I High-dose HD regimens

\begin{tabular}{lllll}
\hline & Conventional HD & SDHD & Long HD & Long-frequent HD \\
\hline Frequency & 3 & $5-6$ & $3-4$ & $5-6$ \\
Duration & 4 & $2-3.5$ & $>5.5$ & $>5.5$ \\
Dialysate flow & $500-800$ & $500-800$ & $300-500$ & $300-500$ \\
Blood flow & $300-400$ & 400 & $200-400$ & $200-300$ \\
Std $K t / V_{\text {urea }}$ & $2.5(12 \mathrm{~h} / \mathrm{wk})$ & $3.75(13.5 \mathrm{~h} / \mathrm{wk})$ & $3.75(26.8 \mathrm{~h} / \mathrm{wk})$ & $5.82(40.2 \mathrm{~h} / \mathrm{wk})$
\end{tabular}

Notes: Frequency in sessions per week; duration in hours per session; dialysate and blood flow in $\mathrm{mL} / \mathrm{min}$. Reprinted from Kidney Int 20I3;83(3), Chan CT, Covic A, Craig JC, et al, Novel techniques and innovation in blood purification: a clinical update from kidney disease: improving global outcomes; 359-37I. Copyright 2013, with permission from Elsevier. ${ }^{21}$

Abbreviations: h, hour; HD, hemodialysis; min, minute; SDHD, short-daily HD; Std Kt/V, standardized Kt/V; wk, week. 
Table 2 Clinical benefits of high-dose HD

\begin{tabular}{lll}
\hline & NHD & SDHD \\
\hline Blood pressure & +++ (PVR reduction) & ++ (ECV reduction) \\
LVH & ++ (afterload & ++ (preload \\
& reduction) & reduction) \\
LV systolic function & +++ & $?$ \\
Arterial compliance & +++ & $?$ \\
Sleep apnea & +++ & $?$ \\
Autonomic nervous system & ++ & $?$ \\
Phosphate & +++ & Varies with dialysis \\
& & duration \\
Anemia & ++ & + \\
Malnutrition & + & ++ \\
Inflammation & $+($ CRP, IL-6) & $+($ CRP) \\
Cognition & ++ & $?$ \\
Fertility & + & $?$ \\
Quality of life & ++ & ++ \\
\hline Notes:? & & ?
\end{tabular}

Notes: '?' indicates it is uncertain what the effect of SDHD is on these parameters. Reprinted from Am J Kidney Dis. 2009;54(6), Perl J, Chan CT. Home hemodialysis, daily hemodialysis, and nocturnal hemodialysis: core curriculum; ||7|-|||84. Copyright 2009, with permission from Elsevier.22

Abbreviations: CRP, C-reactive protein; ECV, effective circulating volume; HD, hemodialysis; IL-6, interleukin-6; LVH, left ventricular hypertrophy NHD, nocturnal HD; PVR, peripheral vascular resistance; SDHD, short-daily HD.

kidney transplantation was associated with superior treatment and patient survival. ${ }^{33}$

Blood pressure (BP) control is one of the most consistent benefits of high-dose HD in randomized and nonrandomized studies. ${ }^{34-40}$ One of the first reports of improved BP control by means of high-dose HD came from Tassin in France where mean ambulatory BP measurements were shown to be inversely correlated with HD session length. ${ }^{41}$ Subsequently, the Frequent Hemodialysis Network (FHN) study showed a significant reduction in systolic BP of $-9.7 \mathrm{mmHg}$ (range from $-16.9 \mathrm{mmHg}$ to $-2.5 \mathrm{mmHg}$ ) during 12 months of follow-up among the NHD cohort, with a significant decrease in the number of antihypertensive agents used. The lack of significant difference in BP readings in patients on a conventional HD prescription (4 hours, three times per week), but performed within the home setting, illustrated the importance of high-dose HD as opposed to location of HD delivery as the main factor driving BP control. ${ }^{37}$ It is widely believed that NHD reduces BP through lowering of total peripheral resistance and plasma norepinephrine levels. ${ }^{39,40}$ SDHD can also lead to improved BP control, but the proposed mechanism of action is thought to be through improved fluid balance. ${ }^{36}$

A number of observational studies of $\mathrm{SDHD}^{36,42}$ and $\mathrm{NHD}^{34,36}$ and an RCT of $\mathrm{NHD}^{43}$ have also shown that intensive HD regimes can be linked to improvements in left ventricular mass index and LVH, both factors associated with poorer outcomes in CKD and dialysis patients. These findings are further supported by a recent meta-analysis of observational studies and data from RCTs that reported improvement in left ventricular mass index and geometry in both frequent and extended HD groups. ${ }^{44}$ Furthermore, Jefferies et al, in a cross-sectional study, demonstrated that more frequent HD regimens were associated with lower ultrafiltration volumes and rates compared with conventional in-center HD. There was an associated significant reduction in episodes of intradialytic systolic hypotension in the SDHD groups, and this was more pronounced in the NHD group. As a consequence, frequent HD regimes were associated with less dialysis-induced myocardial stunning compared with conventional HD. ${ }^{45}$ However, it is worth mentioning that the different groups in the study were not entirely homogeneous in their characteristics. Although the groups were well matched for age, sex, dialysis vintage, and the prevalence of ischemic heart disease, diabetes was more prevalent in the conventional arm. In a randomized crossover study, we recently confirmed improvement of hemodynamic and cardiac stability during extended as opposed to conventional HD sessions. ${ }^{46}$ The observed hemodynamic stability during longer HD treatments involved not only measurements of peripheral systolic BP but also peripheral diastolic and central BP. Cardiac output also exhibited more stability during extended HD sessions, associated with better preservation of relative blood volume during longer dialysis sessions.

The cumulative evidence points toward improved management of LVH, vascular calcifications and cardiovascular outcomes, and bone mineral abnormalities by the use of extended HD and, to a lesser extent, SDHD. ${ }^{37,44,47}$ It is common for patients on long-frequent HD prescriptions to require fewer phosphate-binding medications and on some occasions also need phosphate supplementation in the dialysate. ${ }^{48}$ In the long term, improved control of hyperphosphatemia and secondary hyperparathyroidism by high-dose HD may translate into risk reduction of LVH and vascular calcification.

The impact of high-dose HD on QoL has been the subject of multiple studies, and overall results show an increase in kidney-specific domains of QoL parameters. ${ }^{35,43,49-52}$ This increase in QoL with high-dose HD regimes may be due to increased autonomy and functionality, reduced tablet burden, relaxation of dietary restrictions and fluid intake, considerable reduction to the time spent in hospital and in transit to and from the hospital (as in home HD), the ability to remain in employment (productivity), and a reduction to uremic symptoms. High-dose HD in the home setting has been shown to be associated with mood improvement, an important domain of QoL associated with improved outcomes. ${ }^{43}$ This might be due to improved sleep quality. The FREEDOM study showed a reduction in the prevalence of restless legs 
syndrome from $35 \%$ to $26 \%$ after 12 months of SDHD $(P=0.05),{ }^{53}$ while NHD has been associated with a reduction in the frequency of sleep apnea episodes. ${ }^{54}$

Another important benefit of high-dose HD is its effects on fertility, particularly relevant to young CKD sufferers. Conception rates and pregnancy outcomes are overall poor in patients on dialysis. There are emerging observational data from patients on high-dose HD with lower urea levels that show significantly better outcomes. ${ }^{55,56}$ These findings are also in keeping with the evidence of high-dose HD being associated with the best pregnancy outcomes in patients requiring dialysis. ${ }^{57,58}$ It is thought that the increased rates of successful conception observed in female patients of childbearing age with ESRD receiving high-dose HD may partially be due to restoration of the pituitary-hypothalamic axis augmented by improved solute clearance. At the same time, improved fluid balance, BP control, and hemodynamic stability in high-dose HD could positively impact on pregnancy outcomes. In the male population, high-dose HD could also improve fertility, possibly by increasing testosterone levels and decreasing hyperprolactinemia. ${ }^{59}$

\section{Risks associated with high-dose HD}

The need for more frequent cannulation for frequent HD may potentially lead to increased vascular access-related complications and failure. In the FHN trial, patients on SDHD had a shorter time to first vascular access-related event compared to the conventional HD group. ${ }^{60,61}$ Most of these events were vascular access interventions as opposed to losses. A similar trend was also observed in the nocturnal arm of the FHN study. ${ }^{41,61}$ In our recently performed in-depth review of all available studies looking at vascular access complications in frequent HD compared to conventional HD, we found a small but significantly increased risk of vascular access complications in frequent HD (difference of 6.7 events per 100 patient-years, $P=0.009$ ). These events included access dysfunction, access-related hospital admission, access failure, and access-related infection. ${ }^{62}$

The predominant cannulation method of arteriovenous fistulas and grafts is the rope-ladder technique. Buttonhole (constant-site) cannulation is an alternative technique whereby needles are inserted each time at exactly the same spot using the same insertion angle and the same depth of penetration for each dialysis session. The initial cannulation is performed using sharp needles, and once a subcutaneous tract has been formed, subsequent cannulations are performed using blunt needles. Buttonhole cannulation is commonly used in frequent $\mathrm{HD}$, and it is often preferred by patients because it results in less pain, faster cannulation, and lower risk of hematoma ${ }^{49,63,64}$ However, concerns have been raised recently regarding the safety of this method, especially with regard to track-related infections. Several studies have indeed highlighted the increased risk of local and systemic buttonhole infections in patients on high-dose HD. ${ }^{49,65,66}$

Preservation of residual kidney function (RKF) in dialysis patients is associated with clinical benefits ${ }^{67} \mathrm{~A}$ significant decline in RKF is observed in the first year after dialysis initiation, especially in conventional HD patients. ${ }^{68}$ Recently, the nocturnal FHN study showed a faster reduction in RKF in patients on NHD as compared to conventional HD. ${ }^{69}$ Although this study had significant limitations, these findings were unexpected. The reasons for this observed phenomenon are unclear. Based on the concept of organ hypoperfusion, it would have been expected that the rate of loss of residual function would have been higher in the conventional HD group. A number of mechanisms have been proposed for this loss of RKF and include reduction in osmotic load, an increased inflammatory response, and platelet activation. ${ }^{70}$ More studies are required to understand the reasons behind an accelerated loss of RKF with NHD.

In general, dialysis is associated with cognitive decline, affecting domains such as executive function and attention. The reasons for this are not entirely clear. It could be a result of uremia or cerebral perfusion changes caused during HD. In both of these situations, intensive dialytic regimes should be associated with better outcomes. The FHN study attempted to explore the impacts of intensive dialytics prescriptions but showed no benefit. Interestingly, it raised concerns over both global cognition and attention in the NHD group. However, these data are exploratory, and the study was not powered to answer this question. To investigate the effects of intensive HD on cognition, appropriately powered studies are required. ${ }^{71}$

\section{Who is eligible for high-dose and home HD?}

Patient motivation is essential for the feasibility of both highdose and home HD. There are only few absolute contraindications for these treatments. The suitability of some vascular accesses can be an obstacle to undertaking high-dose HD, while uncontrolled mental health disease, lack of appropriate home environment, and lack of a caregiver (when a person requires assistance with treatment delivery) can all make home HD impossible. ${ }^{72}$

Other known barriers to home HD are lack of motivation/ interest, unwillingness to change, learned helplessness, 
fear of isolation, perceived burden on caregivers, and fear of cannulation. ${ }^{73-75}$ However, these barriers can often be overcome by adequate predialysis education, motivational training of patient and caregiver, nurse-assisted cannulation, nurse-led home visits, a well-defined nursing/technical support system for patients, and provision of respite care. ${ }^{76-78}$

\section{Target populations for high-dose home HD}

All patients going through predialysis education clinic who are capable and willing could be offered the choice of home $\mathrm{HD}$ as a form of a home-based therapy (Figure 1). Some of these patients and those established on a dialysis modality could be targeted for consideration of high-dose home HD. ${ }^{79}$ Patients with ESRD with persistent extracellular fluid overload, severe hypertension and/or LVH, hemodynamic instability, resistant hyperphosphatemia as well as pregnant women or women on dialysis who wish to conceive are established target populations for consideration of high-dose home HD. Sleep apnea, reduced QoL, uremic symptoms, and persistent inflammation/oxidative stress are other factors that should also trigger the consideration of high-dose home HD in a dialysis patient (suggested target population). In addition to these target populations, there are emerging patient groups for whom high-dose home HD may also be considered. These range from caregiver-dependent patients (both patients and caregivers generally prefer a home-based dialysis therapy), crash starters, employed patients, patients with failing transplants, patients with failing PD, and morbid obese and elderly patients with ESRD. ${ }^{80}$ Although the list of target populations for home high-dose HD is extensive, it is by no means exclusive. High-dose HD may be considered for management of rare and challenging conditions such as severe hyperoxaluria where significant benefits of frequent NHD have been reported. ${ }^{81}$

\section{Health economics of high-dose and home HD}

In developed nations, home HD is generally cost-effective compared to hospital-based HD. This was recently confirmed by Walker et $\mathrm{al}^{82}$ who performed a systematic review of full economic evaluations between 2003 and 2014 to analyze the cost-effectiveness of contemporary home HD modalities compared with facility HD. Six such studies were identified. ${ }^{83-88}$ Two of them compared home NHD, one nocturnal and daily home HD, and three compared conventional home HD to facility HD. The main finding of this review was that contemporary home HD modalities including high-dose regimes such as nocturnal and daily HD are cost-neutral or cost-effective compared with conventional facility HD. A variety of reasons can explain why home HD modalities are mostly less expensive compared to in-center HD. These

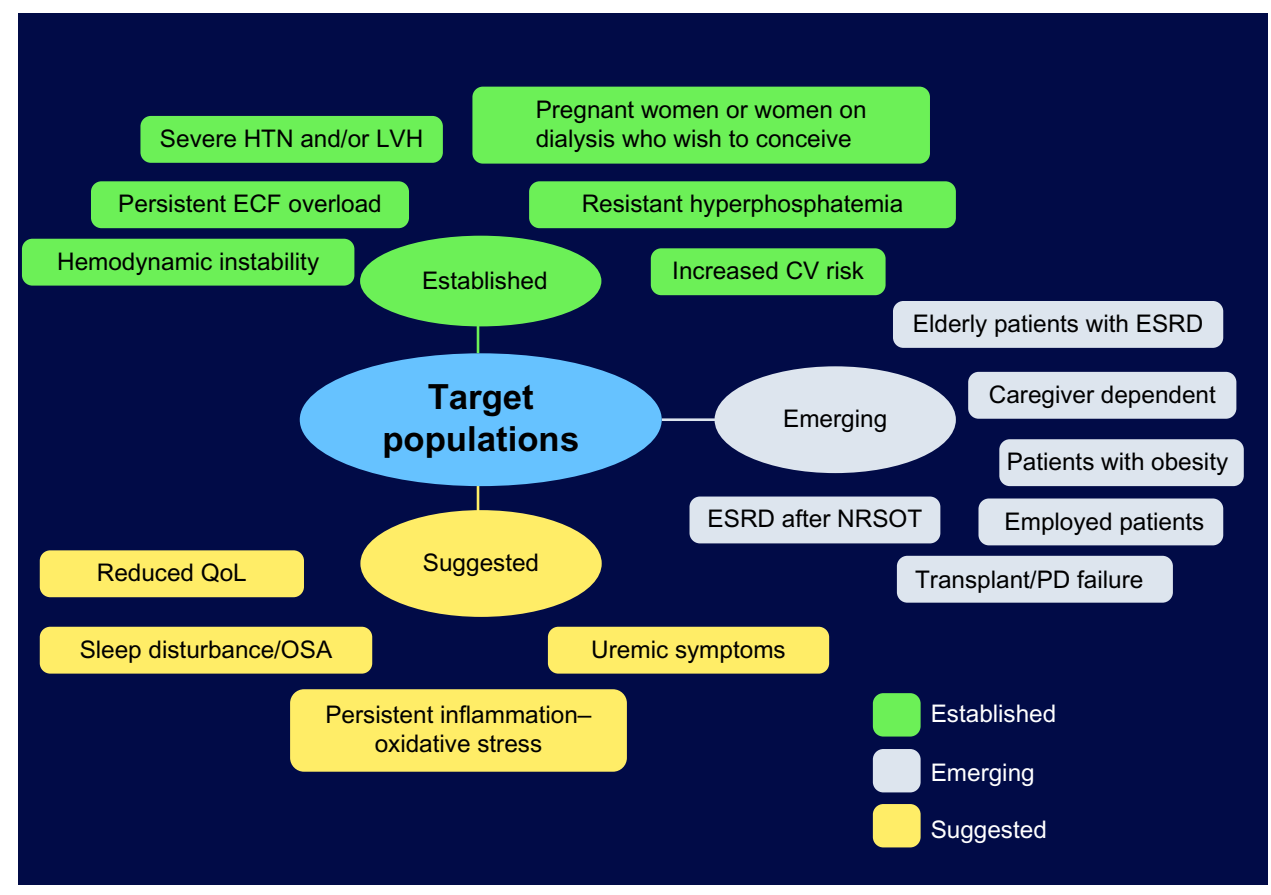

Figure I Target populations for high-dose home HD.

Abbreviations: HD, hemodialysis; HTN, hypertension; LVH, left ventricular hypertrophy; ECF, extracellular fluid; CV, cardiovascular; ESRD, end-stage renal disease; NRSOT, nonrenal solid organ transplantation; QoL, quality of life; PD, peritoneal dialysis; OSA, obstructive sleep apnea. 
include reduced need for expensive hospital space, reduced need for dialysis nurses, increased employment of home dialysis patients, and reduced patient transport costs to and from the dialysis centers.

We performed a preliminary economic analysis of HD modalities in the Netherlands (unpublished data 2016) based on a Markov model, which allows the capture of all possible treatment options for people with ESRD in so-called transition states, including PD, HD, and kidney transplantation (Figure 2) ${ }^{89}$ The objective was to compare the cost-effectiveness of high-dose HD (both in-center and at home) with conventional in-center HD. Key parameters of the analysis were QoL and the survival rates of the studied treatments. We found that treating patients at home with conventional HD costs significantly less than treating them in-center $(-€ 21,205)$ with an additional health benefit $(+0.242$ quality-adjusted life-years). When delivering high-dose dialysis at home, the added health benefit is higher $(+0.478$ quality-adjusted life-years) for what we feel as an acceptable added cost $(+€ 7,795)$. Therefore, we could conclude that in the Netherlands, high-dose home HD appears to be a costeffective alternative to center-based HD.

\section{Future perspectives}

The published work in the field of home therapies and the studied subjects remain small with lack of robust trial-based evidence. Further research is necessary and should be focused on addressing perceived barriers and risks to high-dose HD modalities. Dialysis patients are reliant on health care service delivery and its design for their survival and QoL and productivity. Redesigning dialysis care to being based on the home setting could translate into healthier outcomes and more personalized care, with better self-management.

Convincing patients to dialyze at home should be led by the health care team. A change in attitudes of health care professionals toward home-based dialysis is necessary. A lot of the shortfalls in our approaches may be due to lack of exposure and knowledge of home HD. This could be overcome by incorporating high-dose and home HD education as a core component of training curricula for medical and nursing staff. Experience will indicate that once patients get started on in-center HD, the development of "learned helplessness" makes it more difficult for them to transfer to a home dialysis modality. Investment in redesign of infrastructure is necessary from health care providers to create a dedicated environment preferably outside the hospital setting to deliver home HD training, support, education, and clinics, as well as facilities for respite care, rehabilitation, and social and psychological support.

An area for reevaluating our current practices might be that of transition from predialysis to initiation of dialysis in the home setting. As we previously discussed, although high-dose home HD may be the most suited strategy for maintaining functionality in the first year after initiation of treatment, mainly by reducing dialysis-related complications, ${ }^{90,91}$ it has also been linked with accelerated loss of RKF, increased risk of vascular access complication, and cognitive decline. ${ }^{4,5,71,92,93}$ With this in mind, incremental home HD is a growing practice and reflects the flexibility offered by home therapies. These principles behind incremental dialysis involve initiation of HD two or four times a week for 3 hours (to eliminate the long break) and subsequently titrating dialysis duration and frequency based on clinical parameters and individual preferences. Clinical parameters to assess the required dialysis dose may include the amount of residual renal function, metabolic control (acidosis, hyperkalemia, hyperphosphatemia, secondary hyperparathyroidism), BP regulation, and volume status. Subclinical parameters to evaluate whether an increase in dialysis dose may be required may include various tools such as body composition and hydration status (bio-impedance), presence of myocardial stunning (echocardiography or positron electron tomography), assessment of physical activity (questionnaires, grip strengths, walking speed, SenseWear ${ }^{\circledR}$ device), levels of nontraditional toxins (FGF-23, protein-bound uremic toxins,

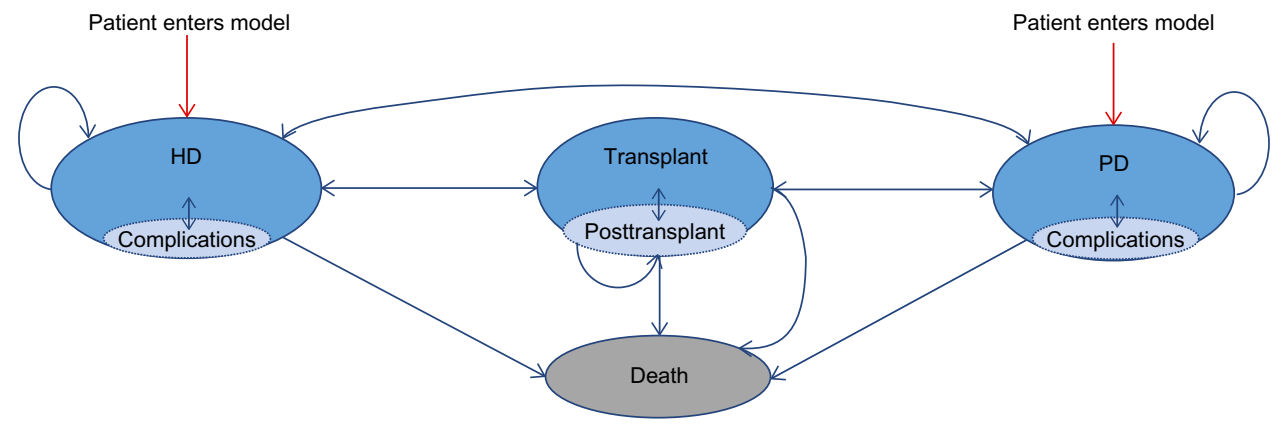

Figure 2 The Markov model.

Note: The Markov model comprises a number of discrete health states through which patients can transition.

Abbreviations: HD, hemodialysis; PD, peritoneal dialysis. 
dicarbonyl stress, and advanced glycation end-products), as well as polysomnography and QoL questionnaires. Recently, Kalantar-Zadeh et $\mathrm{al}^{94}$ studied the effect of incremental HD using an initiation regime of twice-weekly treatments instead of thrice weekly. The objective of their approach was to delay HD-associated loss of residual renal function by reducing the treatment frequency at the time of dialysis initiation. In this study, the clinical factors that would influence transition to more frequent regimes were RKF, volume status, cardiovascular symptoms, body size, potassium and phosphorus levels, comorbid conditions, hospitalizations, and health-related QoL. The cutoff for transition from twice-weekly to thrice-weekly HD was a reduction in urine output below $0.5 \mathrm{~L}$ per day or if the nutritional status or general health condition of the patient was to show a deteriorating trend over time. However, almost all patients starting dialysis based on clinical grounds, as suggested by the IDEAL trial, would by these criteria fail to qualify as suitable candidates to start on twice-weekly HD. ${ }^{95}$ The potential drawbacks of twice-weekly regimen can be significant due to further prolongation of interdialytic intervals, which has been strongly associated with cardiovascular morbidity and mortality. ${ }^{15,96}$ Furthermore, addressing transition from twice- to thrice-weekly regimens as proposed ${ }^{93,94}$ can be difficult from a patient perspective, potentially leading to suboptimal outcomes. ${ }^{96,97}$ The recommendation of a minimum of thrice-weekly dialysis was recently supported by Hakim and Saha ${ }^{98}$ in their review of the effects of dialysis frequency versus dialysis time. The authors also suggest a minimum initial dialysis duration of 4 hours per session, which later could be increased to 6 hours or even 8 hours if clinical and/or subclinical parameters dictate. The debate over the optimal dialysis dosing at the time of transition from predialysis to dialysis and the long-term dose adjustment according to the patient's individual need is still at large, and further studies are required to inform our future strategies. Therefore it is our view that for the majority of patients, the minimum dialysis frequency should be thrice weekly until further evidence of timely initiation of twice-weekly dialysis regimen and its outcomes have been studied. Following their findings, Kalantar-Zadeh et $\mathrm{al}^{94}$ proposed a series of RCTs of incremental versus thrice-weekly HD to further describe the relation between dialysis dosing, frequency, RKF, and patient-related outcomes. High-dose and home HD extends this debate further and provides an opportunity to shift the paradigm from adequate to optimum dialysis.

\section{Disclosure}

The authors report no conflicts of interest in this work.

\section{References}

1. Mitsides N, Keane DF, Lindley E, Mitra S. Technology innovation for patients with kidney disease. J Med Eng Technol. 2015;39(7):424-433.

2. Collins AJ, Foley RN, Herzog C, et al. US Renal Data System 2012 annual data report. Am J Kidney Dis. 2013;61(Suppl 1):A7, e1-e476.

3. Gabbay E, Meyer KB, Griffith JL, Richardson MM, Miskulin DC. Temporal trends in health-related quality of life among hemodialysis patients in the United States. Clin J Am Soc Nephrol. 2010;5(2):261-267.

4. Baigent C, Burbury K, Wheeler D. Premature cardiovascular disease in chronic renal failure. Lancet. 2000;356(9224):147-152.

5. Dalrymple LS, Johansen KL, Chertow GM, et al. Infection-related hospitalizations in older patients with ESRD. Am J Kidney Dis. 2010;56(3):522-530.

6. Shoji T, Tsubakihara Y, Fuji M, Imai E. Hemodialysis-associated hypotension as an independent risk factor for two-year mortality in hemodialysis patients. Kidney Int. 2004;66(3):1212-1220.

7. Burton JO, Jefferies HJ, Selby NM, McIntyre CW. Hemodialysisinduced cardiac injury: determinants and associated outcomes. Clin J Am Soc Nephrol. 2009;4(5):914-920.

8. Burton JO, Jefferies HJ, Selby NM, McIntyre CW. Hemodialysisinduced repetitive myocardial injury results in global and segmental reduction in systolic cardiac function. Clin J Am Soc Nephrol. 2009;4(12):1925-1931.

9. Schneditz D, Roob J, Oswald M, et al. Nature and rate of vascular refilling during dialysis. Kidney Int. 1992;42(6):1425-1433.

10. Kooman JP, Gladziwa U, Bocker G, van Bortel LM, van Hooff JP, Leunissen KM. Role of the venous system in hemodynamics during ultrafiltration and bicarbonate dialysis. Kidney Int. 1992;42(3): 718-726.

11. Santoro A, Mancini E, Spongano M, Rossi M, Paolini F, Zucchelli P. A haemodynamic study of hypotension during hemodialysis using electrical bioimpedance cardiography. Nephrol Dial Transplant. 1990;5(Suppl 1):147-153.

12. van der Sande FM, Kooman JP, Konings CJ, Leunissen KM. Thermal affects and blood pressure response during postdilution hemodiafiltration and hemodialysis: the effect of amount of replacement fluid and dialysate temperature. J Am Soc Nephrol. 2001;12(9):1916-1920.

13. Glassock RJ, Pecoits-Filho R, Barberato SH. Left ventricular mass in chronic kidney disease and ESRD. Clin J Am Soc Nephrol. 2009;4(Suppl 1):S79-S91.

14. Bhan I, Thadhani R. Vascular calcification and ESRD: a hard target. Clin J Am Soc Nephrol. 2009;4(Suppl 1):S102-S105.

15. Foley RN, Gilbertson DT, Murray T, Collins AJ. Long interdialytic interval and mortality among patients receiving hemodialysis. $N$ Engl J Med. 2011;365(12):1099-1107.

16. George CR. History of home haemodialysis in Australia. Nephrology (Carlton). 2005;10(3):215-221.

17. Woods JD, Port FK, Stannard D, Blagg CR, Held PJ. Comparison of mortality with home hemodialysis and center hemodialysis: a national study. Kidney Int. 1996;49(5):1464-1470.

18. Bremer BA, McCauley CR, Wrona RM, Johnson JP. Quality of life in end-stage renal disease: a reexamination. Am J Kidney Dis. 1989;13(3):200-209.

19. Lee H, Manns B, Taub K, et al. Cost analysis of ongoing care of patients with end-stage renal disease: the impact of dialysis modality and dialysis access. Am J Kidney Dis. 2002;40(3):611-622.

20. Charra B, Calemard E, Ruffet M, et al. Survival as an index of adequacy of dialysis. Kidney Int. 1992;41(5):1286-1291.

21. Chan CT, Covic A, Craig JC, et al. Novel techniques and innovation in blood purification: a clinical update from kidney disease: improving global outcomes. Kidney Int. 2013;83(3):359-371.

22. Perl J, Chan CT. Home hemodialysis, daily hemodialysis, and nocturnal hemodialysis: core curriculum 2009. Am J Kidney Dis. 2009;54(6):1171-1184.

23. Kjellstrand C, Buoncristiani U, Ting G, et al. Survival with short-daily hemodialysis: assocation of time, site, and dose of dialysis. Hemodial Int. 2010;14(4):464-470. 
24. Jun M, Jardine MJ, Gray N, et al. Outcomes of extended-hours hemodialysis performed predominantly at home. Am J Kidney Dis. 2013;61(2):247-253.

25. Pauly RP, Maximova K, Coppens J, et al; CAN-SLEEP Collaborative Group. Patient and technique survival among a Canadian multicenter nocturnal home hemodialysis cohort. Clin J Am Soc Nephrol. 2010;5(10):1815-1820.

26. Blagg CR, Kjellstrand CM, Ting GO, Young BA. Comparison of survival between short-daily hemodialysis and conventional hemodialysis using the standardized mortality ratio. Hemodial Int. 2006;10(4):371-374.

27. Weinhandl ED, Liu J, Gilbertson DT, Arenson TJ, Collins AJ. Survival in daily home hemodialysis and matched thrice-weekly in-center hemodialysis patients. J Am Soc Nephrol. 2012;23(5):895-904.

28. Nesrallah GE, Lindsay RM, Cuerden MS, et al. Intensive hemodialysis associates with improved survival as compared with conventional hemodialysis. J Am Soc Nephrol. 2012;23(4):696-705.

29. Johansen KL, Zhang R, Huang Y, et al. Survival and hospitalization among patients using nocturnal and short daily compared to conventional hemodialysis: a USRDS study. Kidney Int. 2009;76(9):984-990.

30. Lockridge RS, Kjellstrand CM. Nightly home hemodialysis: outcome and factors associated with survival. Hemodial Int. 2011;15(2):211-228.

31. Kjellstrand CM, Buoncristiani U, Ting G, et al. Short daily haemodialysis: survival in 415 patients treated for 1006 patient-years. Nephrol Dial Transplant. 2008;23(10):3283-3289.

32. Pauly RP, Gill JS, Rose CL, et al. Survival among nocturnal home haemodialysis patients compared to kidney transplant recipients. Nephrol Dial Transplant. 2009;24(9):2915-2919.

33. Tennankore KK, Kim SJ, Baer HJ, Chan CT. Survival and hospitalization for intensive home hemodialysis compared with kidney transplantation. J Am Soc Nephrol. 2014;25(9):2113-2120.

34. Chan CT, Floras JS, Miller JA, Richardson RM, Pierratos A. Regression of left ventricular hypertrophy after conversion to nocturnal hemodialysis. Kidney Int. 2002;61(6):2235-2239.

35. Lockridge RS Jr, Spencer M, Craft V, et al. Nightly home hemodialysis: five and one-half years of experience in Lynchburg, Virginia. Hemodial Int. 2004;8(1):61-69.

36. Nesrallah G, Suri R, Moist L, Kortas C, Lindsay R. Volume control and blood pressure management in patients undergoing quotidian hemodialysis. Am J Kidney Dis. 2003;42(Suppl 1):13-17.

37. Rocco MV, Lockridge RS Jr, Beck GJ, et al; Frequent Hemodialysis Network (FHN) Trial Group. The effects of frequent nocturnal home hemodialysis: the frequent hemodialysis network nocturnal trial. Kidney Int. 2011;80(10):1080-1091.

38. Kraus M, Burkart J, Hegeman R, Solomon R, Coplon N, Moran J. A comparison of centerbased vs. home-based daily hemodialysis for patients with endstage renal disease. Hemodial Int. 2007;11(4): 468-477.

39. McGregor DO, Buttimore AL, Lynn KL, Nicholls MG, Jardine DL. A comparative study of blood pressure control with short in-center versus long home hemodialysis. Blood Purif. 2001;19(3):293-300.

40. Chan CT, Harvey PJ, Picton P, Pierratos A, Miller JA, Floras JS. Shortterm blood pressure, noradrenergic, and vascular effects of nocturnal home hemodialysis. Hypertension. 2003;42(5):925-931.

41. Chazot C, Charra B, Laurent G, et al. Interdialysis blood pressure control by long haemodialysis sessions. Nephrol Dial Transplant. 1995;10(6):831-837.

42. Fagugli RM, Reboldi G, Quintaliani G, et al. Short daily hemodialysis: blood pressure control and left ventricular mass reduction in hypertensive hemodialysis patients. Am J Kidney Dis. 2001;38(2):371-376.

43. Culleton BF, Walsh M, Klarenbach SW, et al. Effect of frequent nocturnal hemodialysis vs conventional hemodialysis on left ventricular mass and quality of life: a randomized controlled trial. JAMA. 2007; 298(11):1291-1299.

44. Susantitaphong P, Koulouridis I, Balk EM, Madias NE, Jaber BL. Effect of frequent or extended hemodialysis on cardiovascular parameters: a metaanalysis. Am J Kidney Dis. 2012;59(5):689-699.
45. Jefferies HJ, Virk B, Schiller B, Moran J, McIntyre CW. Frequent hemodialysis schedules are associated with reduced levels of dialysisinduced cardiac injury (myocardial stunning). Clin J Am Soc Nephrol. 2011;6(6):1326-1332.

46. Cornelis T, van der Sande FM, Eloot S, et al. Acute hemodynamic response and uremic toxin removal in conventional and extended hemodialysis and hemodiafiltration: a randomized crossover study. Am J Kidney Dis. 2014;64(2):247-256.

47. Walsh M, Manns BJ, Klarenbach S, Tonelli M, Hemmelgarn B, Culleton B. The effects of nocturnal compared with conventional hemodialysis on mineral metabolism: a randomized-controlled trial. Hemodial Int. 2010;14(2):174-181.

48. Ebah LM, Akhtar M, Wilde I, et al. Phosphate enrichment of dialysate for use in standard and extended haemodialysis. Blood Purif. 2012;34(1):28-33.

49. Jaber BL, Lee Y, Collins AJ, et al; FREEDOM Study Group. Effect of daily hemodialysis on depressive symptoms and postdialysis recovery time: interim report from the FREEDOM (following rehabilitation, economics and everyday-dialysis outcome measurements) study. Am J Kidney Dis. 2010;56(3):531-539.

50. van Eps CL, Jeffries JK, Johnson DW, et al. Quality of life and alternate nightly nocturnal home hemodialysis. Hemodial Int. 2010;14(1):29-38.

51. Vos PF, Zilch O, Jennekens-Schinkel A, et al. Effect of short daily home haemodialysis on quality of life, cognitive functioning and the electroencephalogram. Nephrol Dial Transplant. 2006;21(9): 2529-2535.

52. Heidenheim AP, Muirhead N, Moist L, Lindsay RM. Patient quality of life on quotidian hemodialysis. Am J Kidney Dis. 2003;42(Suppl 1): 36-41.

53. Jaber BL, Schiller B, Burkart JM, et al; FREEDOM Study Group. Impact of short daily hemodialysis on restless legs symptoms and sleep disturbances. Clin J Am Soc Nephrol. 2011;6(5):1049-1056.

54. Hanly PJ, Pierratos A. Improvement of sleep apnea in patients with chronic renal failure who undergo nocturnal hemodialysis. $N$ Engl J Med. 2001;344(2):102-107.

55. Okundaye I, Abrinko P, Hou S. Registry of pregnancy in dialysis patients. Am J Kidney Dis. 1998;31(5):766-773.

56. Asamiya Y, Otsubo S, Matsuda Y, et al. The importance of low blood urea nitrogen levels in pregnant patients undergoing hemodialysis to optimize birth weight and gestational age. Kidney Int. 2009;75(11):1217-1222.

57. Barua M, Hladunewich M, Keunen J, et al. Successful pregnancies on nocturnal home hemodialysis. Clin J Am Soc Nephrol. 2008; 3(2):392-396.

58. Hladunewich MA, Hou S, Odutayo A, et al. Intensive hemodialysis is associated with improved pregnancy outcomes: a Canadian and United States comparison. J Am Soc Nephrol. 2014;25(5):1103-1109.

59. van Eps C, Hawley C, Jeffries J, et al. Changes in serum prolactin, sex hormones and thyroid function with alternate nightly nocturnal home haemodialysis. Nephrology (Carlton). 2012;17(1):42-47.

60. Chertow GM, Levin NW, Beck GJ, et al. FHN Trial Group. In-center hemodialysis six times per week versus three times per week. $N$ Engl J Med. 2010;363(24):2287-2300.

61. Suri RS, Larive B, Sherer S, et al; Frequent Hemodialysis Network Trial Group. Risk of vascular access complications with frequent hemodialysis. J Am Soc Nephrol. 2013;24(3):498-505.

62. Cornelis T, Usvyat LA, Tordoir JH, et al. Vascular access vulnerability in intensive hemodialysis: a significant Achilles' heel? Blood Purif. 2014;37(3):222-228.

63. Leitch R, Ouwendyk M, Ferguson E, et al. Nursing issues related to patient selection, vascular access, and education in quotidian hemodialysis. Am J Kidney Dis. 2003;42(Suppl 1):56-60.

64. Verhallen AM, Kooistra MP, van Jaarsveld BC. Cannulating in hemodialysis: rope-ladder or buttonhole technique? Nephrol Dial Transplant. 2007;22(9):2601-2604. 
65. MacRae JM, Ahmed SB, Atkar R, Hemmelgarn BR. A randomized trial comparing buttonhole with rope ladder needling in conventional hemodialysis patients. Clin J Am Soc Nephrol. 2012;7(10): $1632-1638$.

66. Nesrallah GE, Cuerden M, Wong JH, Pierratos A. Staphylococcus aureus bacteremia and buttonhole cannulation: long-term safety and efficacy of mupirocin prophylaxis. Clin J Am Soc Nephrol. 2010;5(6):1047-1053.

67. Vilar E, Farrington K. Emerging importance of residual renal function in end-stage renal failure. Semin Dial. 2011;24(4):487-494.

68. Jansen MA, Hart AA, Korevaar JC, et al; NECOSAD Study Group. Predictors of the rate of decline of residual renal function in incident dialysis patients. Kidney Int. 2002;62(3):1046-1053.

69. Daugirdas JT, Greene T, Rocco MV, et al; FHN Trial Group. Effect of frequent hemodialysis on residual kidney function. Kidney Int. 2013;83(5):949-958

70. Daugirdas JT, Bernardo AA. Hemodialysis effect on platelet count and function and hemodialysis-associated thrombocytopenia. Kidney Int 2012;82(2):147-157.

71. Kurella Tamura M, Unruh ML, Nissenson AR, et al; Frequent Hemodialysis Network (FHN) Trial Group. Effect of more frequent hemodialysis on cognitive function in the frequent hemodialysis network trials. Am J Kidney Dis. 2013;61(2):228-237.

72. Rioux JP, Faratro R, Chan CT. Nocturnal home hemodialysis: implementation, quality assurance and future challenges. Minerva Urol Nefrol. 2010;62(1):103-110.

73. McLaughlin K, Manns B, Mortis G, Hons R, Taub K. Why patients with ESRD do not select self-care dialysis as a treatment option. Am J Kidney Dis. 2003;41(2):380-385.

74. Zhang AH, Bargman JM, Lok CE, et al. Dialysis modality choices among chronic kidney disease patients: identifying the gaps to support patients on home-based therapies. Int Urol Nephrol. 2010;42(3):759-764.

75. Cafazzo JA, Leonard K, Easty AC, Rossos PG, Chan CT. Patientperceived barriers to the adoption of nocturnal home hemodialysis. Clin J Am Soc Nephrol. 2009;4(4):784-789.

76. Pipkin M, Eggers PW, Larive B, et al; Frequent Hemodialysis Network Trial Group. Recruitment and training for home hemodialysis: experience and lessons from the nocturnal dialysis trial. Clin J Am Soc Nephrol. 2010;5(9):1614-1620.

77. Morton RL, Tong A, Webster AC, Snelling P, Howard K. Characteristics of dialysis important to patients and family caregivers: a mixed methods approach. Nephrol Dial Transplant. 2011;26(12):4038-4046.

78. Agar JW. Home hemodialysis in Australia and New Zealand: practical problems and solutions. Hemodial Int. 2008;12(Suppl 1): S26-S32.

79. Tennankore K, Nadeau-Fredette A-C, Chan CT. Intensified home hemodialysis: clinical benefits, risks and target populations. Nephrol Dial Transplant. 2014;29(7):1342-1349.

80. Cornelis T, Tennankore KT, Goffin E, et al. An international feasibility study of home hemodialysis in older patients. Nephrol Dial Transplant. 2014;29(12):2327-2333.
81. Plumb TJ, Swee ML, Fillaus JA. Nocturnal home hemodialysis for a patient with type 1 hyperoxaluria. Am J Kidney Dis. 2013;62(6): 1155-1159.

82. Walker R, Marshall MR, Morton RL, McFarlane P, Howard K. The cost-effectiveness of contemporary home haemodialysis modalities compared with facility haemodialysis: a systematic review of full economic evaluations. Nephrology. 2014;19(8):459-470.

83. McFarlane PA, Bayoumi AM, Pierratos A, Redelmeier DA. The quality of life and cost utility of home nocturnal and conventional in-center hemodialysis. Kidney Int. 2003;64(3):1004-1011.

84. Kroeker A, Clark WF, Heidenheim AP, et al. An operating cost comparison between conventional and home quotidian hemodialysis. Am J Kidney Dis. 2003;1(Suppl 1):49-55.

85. Gonzalez-Perez JG, Vale L, Stearns SC, Wordsworth S. Hemodialysis for end-stage renal disease: a cost-effectiveness analysis of treatmentoptions. Int J Technol Assess Health Care. 2005;21(1):32-39.

86. Malmstrom RK, Roine RP, Heikkila A, et al. Cost analysis and healthrelated quality of life of home and self-care satellite haemodialysis. Nephrol Dial Transplant. 2008;23(6):1990-1996.

87. Howard K, Salkeld G, White S, et al. The cost-effectiveness of increasing kidney transplantation and home-based dialysis. Nephrology. 2009;14(1):123-132.

88. Klarenbach S, Tonelli M, Pauly R, et al. Economic evaluation of frequent home nocturnal hemodialysis based on a randomized controlled trial. J Am Soc Nephrol. 2014;25(3):587-594.

89. Kirby L, Vale L. Dialysis for end-stage renal disease. Determining a cost-effective approach. Int J Technol Assess Health Care. 2001; 17(2):181-189.

90. Cornelis T, Kooman J, van der Sande F. Just-in-time initiation of optimal dialysis. Ned Tijdschr Geneeskd. 2010;154:A2549.

91. Cornelis T, van der Sande FM, Kooman JP. Balancing transition to dialysis: the urgent need for more intensive hemodialysis. Kidney Int 2013;83(5):967-968.

92. Berns JS, Dember LM. Can frequent hemodialysis be too frequent? J Am Soc Nephrol. 2013;24(3):334-336.

93. Farrington K. Commentary for "Effect of frequent hemodialysis on residual kidney function": frequent hemodialysis network (FHN) trials. Kidney Int. 2013;83(5):787-789.

94. Kalantar-Zadeh K, Unruh M, Zager PG, et al. Twice-weekly and incremental hemodialysis treatment for initiation of kidney replacement therapy. Am J Kidney Dis. 2014;64(2):181-186.

95. Cooper BA, Branley P, Bulfone L, et al; IDEAL Study. A randomized, controlled trial of early versus late initiation of dialysis. $N$ Engl J Med. 2010;363(7):609-619.

96. Vanholder R, Van Biesen W, Lameire N. Is starting hemodialysis on a twice-weekly regimen a valid option? Am J Kidney Dis. 2014 64(2):165-167.

97. Collins AJ, Foley RN, Chavers B, et al. US Renal Data System 2013 annual data report. Am J Kidney Dis. 2014;63(Suppl 1):A7.

98. Hakim RM, Saha S. Dialysis frequency versus dialysis time, that is the question. Kidney Int. 2014;85(5):1024-1029.

International Journal of Nephrology and Renovascular Disease

\section{Publish your work in this journal}

The International Journal of Nephrology and Renovascular Disease is an international, peer-reviewed open-access journal focusing on the pathophysiology of the kidney and vascular supply. Epidemiology, screening, diagnosis, and treatment interventions are covered as well as basic science, biochemical and immunological studies. The journal welcomes

\section{Dovepress}

original research, clinical studies, reviews \& evaluations, expert opinion and commentary, case reports and extended reports. The manuscript management system is completely online and includes a very quick and fair peerreview system, which is all easy to use. Visit http://www.dovepress.com/ testimonials.php to read real quotes from published authors. 